Article

\title{
Effects of Psychostimulants and Antipsychotics on Serum Lipids in an Animal Model for Schizophrenia
}

\author{
Banny Silva Barbosa Correia ${ }^{1}{ }^{\circledR}$, João Victor Nani ${ }^{2,3}{ }^{\circledR}$, Raniery Waladares Ricardo ${ }^{1}$, Danijela Stanisic ${ }^{1}$, \\ Tássia Brena Barroso Carneiro Costa ${ }^{1}$ (), Mirian A. F. Hayashi ${ }^{2,3, *}$ and Ljubica Tasic ${ }^{1, *(\mathbb{C}}$ \\ 1 Instituto de Química, Universidade Estadual de Campinas (UNICAMP), Campinas 13083-970, Brazil; \\ banny.barbosa@gmail.com (B.S.B.C.); raniery014@gmail.com (R.W.R.); danijela@unicamp.br (D.S.); \\ tassiabrena@gmail.com (T.B.B.C.C.) \\ 2 Departamento de Farmacologia, Escola Paulista de Medicina (EPM), Universidade Federal de São \\ Paulo (UNIFESP), São Paulo 04044-020, Brazil; joaoonanii@gmail.com \\ 3 National Institute for Translational Medicine (INCT-TM, CNPq), Faculdade de Medicina de Ribeirão Preto da \\ Universidade de São Paulo (FMRP-USP), São Paulo 14049-900, Brazil \\ * Correspondence: mhayashi@unifesp.br (M.A.F.H.); ljubica@unicamp.br (L.T.); \\ Tel.: +55-11-5576-4447 (M.A.F.H.); +55-19-3521-1106 (L.T.); \\ Fax: +55-11-5576-4499 (M.A.F.H.); +55-19-3521-3023 (L.T.)
}

check for

updates

Citation: Correia, B.S.B.; Nani, J.V.; Waladares Ricardo, R.; Stanisic, D.; Costa, T.B.B.C.; Hayashi, M.A.F.;

Tasic, L. Effects of Psychostimulants and Antipsychotics on Serum Lipids in an Animal Model for Schizophrenia. Biomedicines 2021, 9, 235. https://doi.org/10.3390/ biomedicines 9030235

Academic Editor: Masaru Tanaka

Received: 4 December 2020

Accepted: 2 February 2021

Published: 26 February 2021

Publisher's Note: MDPI stays neutral with regard to jurisdictional claims in published maps and institutional affiliations.

Copyright: (c) 2021 by the authors. Licensee MDPI, Basel, Switzerland. This article is an open access article distributed under the terms and conditions of the Creative Commons Attribution (CC BY) license (https:// creativecommons.org/licenses/by/ $4.0 /)$
Abstract: Schizophrenia (SCZ) treatment is essentially limited to the use of typical or atypical antipsychotic drugs, which suppress the main symptoms of this mental disorder. Metabolic syndrome is often reported in patients with SCZ under long-term drug treatment, but little is known about the alteration of lipid metabolism induced by antipsychotic use. In this study, we evaluated the blood serum lipids of a validated animal model for SCZ (Spontaneously Hypertensive Rat, SHR), and a normal control rat strain (Normotensive Wistar Rat, NWR), after long-term treatment (30 days) with typical haloperidol (HAL) or atypical clozapine (CLZ) antipsychotics. Moreover, psychostimulants, amphetamine (AMPH) or lisdexamfetamine (LSDX), were administered to NWR animals aiming to mimic the human first episode of psychosis, and the effects on serum lipids were also evaluated Discrepancies in lipids between SHR and NWR animals, which included increased total lipids and decreased phospholipids in SHR compared with NWR, were similar to the differences previously reported for SCZ patients relative to healthy controls. Administration of psychostimulants in NWR decreased omega-3, which was also decreased in the first episode of psychosis of SCZ. Moreover, choline glycerophospholipids allowed us to distinguish the effects of CLZ in SHR. Thus, changes in the lipid metabolism in SHR seem to be reversed by the long-term treatment with the atypical antipsychotic CLZ, which was under the same condition described to reverse the SCZ-like endophenotypes of this validated animal model for SCZ. These data open new insights for understanding the potential influence of the treatment with typical or atypical antipsychotics on circulating lipids. This may represent an outcome effect from metabolic pathways that regulate lipids synthesis and breakdown, which may be reflecting a cell lipids dysfunction in SCZ.

Keywords: lipidomics; schizophrenia; animal models; antipsychotics

\section{Introduction}

Schizophrenia (SCZ) is a severe, complex and chronic mental disorder (MD), with a serious impact on patients and their families and caretakers. This highly disabling MD imposes an unemployment rate of about $80 \%$, in addition to an important reduction in the life expectancy of patients, which is estimated to be shortened up by about 20 years compared to the general population without psychiatric dysfunctions [1]. In general, SCZ patients are characterized by positive symptoms such as delusions, hallucinations, psychosis, or negative symptoms, which include impaired motivation, reduction in spontaneous speech and social withdrawal, emotional processing/cognitive deficits, and may possibly include impaired neurocognitive deficits, confused speech or behavior alterations $[2,3]$. 
The most accepted theory to explain the neurobiology of SCZ is based on abnormalities in neurotransmission, as for instance, the alterations in dopaminergic, serotoninergic, glutamatergic, among other signaling pathways [1,4]. The main drugs used to treat SCZ symptoms are antipsychotic drugs, which are usually employed to normalize the dysfunctions in neurotransmission. Although antipsychotic drugs can control the main symptoms of SCZ, the disease progression is not stopped by long-term treatments with antipsychotics [5]. Another pathway implicated in SCZ pathophysiology is the kynurenine pathway (KP), which involves the tryptophan metabolism [6]. The KP metabolites modulate neurotransmitters related to cognition [7]. Individuals with MDs presented lower levels of kynurenines, which may be involved in cognitive impairment [8], while conversely, SCZ patients showed increased kynurenine levels [6,8]. Therefore, tryptophankynurenine metabolism in psychiatric disease is well established, and disturbance of the tryptophan-kynurenine metabolic pathway might be a promising target to unravel the therapeutic effects of psychoactive drugs. Additionally, the KP is also related to lipid metabolism [6,7].

Several studies have pointed to some abnormalities in cell membranes and brain lipids that compromise the structural integrity and functional properties of neurons in patients with MD $[9,10]$. Moreover, insufficient uptake, excessive breakdown and/or changes in membrane phospholipids composition are all associated with SCZ and dysfunctional synapses [9-11]. The analytical evaluation of the effects of drugs currently employed in clinics is of utmost importance for the progress in the knowledge in the field. For this purpose, optimized animal models have the power to contribute for understanding the pharmacological effects of each class of antipsychotics on animal metabolism and, consequently, to the discovery of new pathways underlying complex diseases such as MDs [12].

The Spontaneously Hypertensive Rat (SHR) strain was recognized as a reliable animal model for studying SCZ due to the depicted SCZ-like behaviors, which were reversed by the treatment with typical and atypical antipsychotics [13,14]. It is worth mentioning that these animal behavior alterations following the treatment with antipsychotics were not associated with the high blood pressure of adult SHR [15], although they were associated with differences in biochemical biomarkers in blood serum and brain from SHR compared with normotensive Wistar rats (NWR) $[14,16]$. Moreover, these altered levels of biochemical biomarkers in SHR relative to NWR were also observed in SCZ compared with healthy control subjects [17-19], reinforcing the validity of this animal model for studying pathophysiological pathways associated with this psychiatric disorder.

The power of analytical approaches for lipid metabolism in neuropsychiatric disorders is increasingly recognized [20-23], and a better understanding of blood lipids could potentially add important knowledge. Nuclear magnetic resonance (NMR) spectroscopy is a powerful analytical tool that provides relevant information for comparison of different samples, and allows the identification of lipids [24]. In the present study, we tested the alterations in the lipid content by comparing the effects of typical haloperidol (HAL) and atypical clozapine (CLZ) antipsychotic drugs after 30 days of treatment of a validated animal model for studying SCZ (namely SHR), which were compared with a control normal strain (namely NWR). In addition, to mimic the increases of dopamine release, expected to occur in episodes of psychosis, NWR animals were challenged by acute administration of psychostimulants-amphetamine (AMPH) or lisdexamfetamine (LSDX) [16]—for blood lipid contents evaluation. Herein, the lipidomics by NMR analyses aimed to identify potential changes in lipids that could provide insights into the metabolic consequences of the pharmacological interventions with pro-psychotic psychostimulants or antipsychotics employing animal models. These results may contribute to the understanding of the metabolic effects of the treatments of SCZ patients with typical or atypical antipsychotics under clinical conditions. 


\section{Materials and Methods}

\subsection{Animals}

Spontaneously Hypertensive Rat (SHR) and normotensive Wistar rat (NWR) strains were treated under previously described conditions [13-16]. Male 4-5 months-old animals, from our own local colony, were housed in groups of 3-4 animals per cage $\left(41 \times 34 \times 16.5 \mathrm{~cm}^{3}\right)$, under controlled temperature $\left(22-23^{\circ} \mathrm{C}\right)$ and $12 / 12 \mathrm{~h}$ light/dark cycle conditions, with lights on at 07:00 AM, and with free access to water and a normocaloric Nuvilab CR-1 irradiated diet (Quimtia ${ }^{\circledR}$, Curitiba, Brazil). The animals were maintained following the guidelines of the Committee on Care and Use of Laboratory Animal Resources, National Research Council, USA. This study was approved by the Ethical Committee of the Universidade Federal de São Paulo (UNIFESP/EPM), identification CEUA No 7290170315, approved on 15 March 2015.

\subsection{Reagents and Drugs}

The solvents (chloroform, methanol, and acetone) used for lipids extraction were from LabSynth Products Laboratories (Diadema, SP, Brazil), and deuterated chloroform $\left(\mathrm{CDCl}_{3}\right.$, with $99.8 \%$ of $\left.\mathrm{D}\right)$ was from Cambridge Isotope Laboratories, Inc. (Tewksbury, MA, USA). Other reagents were of analytical grade from Sigma-Aldrich (St. Louis, MI, USA). Antipsychotics haloperidol (HAL, Sigma-Aldrich, St. Louis, MO, USA) and clozapine (CLZ, Pinazan, Laboratório Cristália, São Paulo, Brazil), as well as the psychostimulants amphetamine (AMPH, Sigma-Aldrich) and lisdexamfetamine dimesylate (LSDX, Vynvase ${ }^{\mathrm{TM}}$, Shire LLC, São Paulo, Brazil), were dissolved in saline solution, and they were injected by intraperitoneal (ip) route in a volume of $1 \mathrm{~mL} / \mathrm{kg}$ of animal body weight. The volume of the vehicle administered for the negative controls was also $1 \mathrm{~mL} / \mathrm{kg}$ of animal body weight.

\subsection{Drug-Nä̈ve Animals}

The blood samples of drug-naïve NWR and SHR male animals (5 months-old) were collected in dry blood tubes, soon after the animal euthanasia by decapitation, strictly following the standards described in the Guidelines for Ethical Conduct in the Care and Use of Animals.

\subsection{Treatment with Psychostimulants}

Male NWR (5 months-old) were grouped in each cage with 4-5 animals, and a single dose of the propsychotic psychostimulants $(0.5$ or $5.0 \mathrm{mg} / \mathrm{kg})$, namely AMPH or LSDX, was administered by ip route, aiming to mimic the SCZ-like psychotic episodes [13]. Before (baseline) and $2 \mathrm{~h}$ after this single ip injection of either psychostimulants, the blood of the animals was collected in heparin tubes by tail punction.

\subsection{Treatment with Antipsychotics}

Male NWR and SHR (4 months-old) animals were kept in cages for a month to acclimate before starting the daily treatment for 30 days. This treatment was performed exactly as previously described to evaluate and reverse the characteristic SCZ-like behavioral and biochemical changes $[13,14,16]$. Then, animals were grouped into: Group I-control animals receiving vehicle (saline $0.9 \%, 0.1 \mathrm{~mL} / \mathrm{kg}$, ip); Group II: animals treated with HAL (0.5 mg/kg, ip); and Group III: animals treated daily with CLZ (2.5 mg/kg, ip). At the end of the treatments, one day after the last administration of antipsychotics (experimental groups) or saline vehicle (negative control group), the blood was collected in dry blood tubes, soon after the euthanasia of animals by decapitation.

Sixty-one animal serum samples underwent lipids extraction and subsequent proton NMR ( $\left.{ }^{1} \mathrm{H}-\mathrm{NMR}\right)$ analysis. The serum samples from animals were:

(a) non-treated animal strains, NWR (control group, N =4), and SHR (SCZ group, $\mathrm{N}=4$ ), with a total animal serum sample equal to 8;

(b) NWR animals challenged with psychostimulants (AMPH or LSDX) and controls receiving saline, in which: 
(1) NWR receiving saline $0.9 \%(\mathrm{~N}=5)$; (2) NWR receiving single administration of $0.5 \mathrm{mg} / \mathrm{kg}(\mathrm{N}=5)$ or $5.0 \mathrm{mg} / \mathrm{kg}(\mathrm{N}=5)$ of AMPH; (3) NWR receiving single administration of $0.5 \mathrm{mg} / \mathrm{kg}(\mathrm{N}=5)$ or $5.0 \mathrm{mg} / \mathrm{kg}(\mathrm{N}=5)$ of LSDX, with a total animal serum samples equal to 25;

(c) treatment with antipsychotics for 30 days: (1) NWR receiving saline $0.9 \%(\mathrm{~N}=4)$; (2) SHR receiving saline $0.9 \%(\mathrm{~N}=4)$; (3) NWR treated with CLZ $(\mathrm{N}=5)$; (4) NWR treated with HAL ( $=5)$; (5) SHR treated with CLZ ( $=5)$; (6) SHR treated with HAL ( $=5)$, with a total animal serum samples equal to 28 .

\subsection{Extraction of Lipids from Serum Samples and NMR Analysis}

Animal serum $(0.5 \mathrm{~mL})$ was mixed for $1 \mathrm{~min}$, using a vortex, with $2.4 \mathrm{~mL}$ of the solvent mixture composed of methanol: chloroform: sodium chloride solution $(0.15 \mathrm{~mol} / \mathrm{L})$ in a ratio of 1:2:2 $(v / v / v)$. Then, the mixture was centrifuged for $20 \mathrm{~min}$ at $2200 \times g$ at $10{ }^{\circ} \mathrm{C}$, and the chloroform phase that contained serum lipids was carefully separated from the hydro-alcoholic phase. Chloroform was evaporated and obtained samples were weighted and stored at $-20^{\circ} \mathrm{C}$ until the analysis by NMR [24].

Lipids $(10 \mathrm{mg})$ were dissolved in $600 \mu \mathrm{L}$ of $99.8 \%$ deuterated chloroform $\left(\mathrm{CDCl}_{3}\right.$, Cambridge Isotope Laboratories, Inc.) and were transferred into the NMR tubes (5 $\mathrm{mm}$ ) and kept at $4{ }^{\circ} \mathrm{C}$, to avoid the chloroform evaporation and/or lipid oxidation. ${ }^{1} \mathrm{H}-\mathrm{NMR}$ analyses were conducted in a Bruker Avance III NMR $600 \mathrm{MHz}$ spectrometer equipped with the Triple Resonance Broad Band NMR probe (Bruker Corp., Billerica, MA, USA). ${ }^{1} \mathrm{H}-\mathrm{NMR}$ spectra were recorded at $25^{\circ} \mathrm{C}$ with the acquisition time of $2.66 \mathrm{~s}$, spectral window width of $26.564 \mathrm{~Hz}$, relaxation time decay (relaxation delay) of $2 \mathrm{~s}$, and 128 number of scans.

For quantitative analysis, some representative samples were chosen and prepared by adding $100 \mu \mathrm{L}$ of the standard solution of 1,2,4,5-tetrachloro-3-nitrobenzene $(5 \mathrm{mg} / \mathrm{mL}$, 99.86\% purity; Sigma-Aldrich) into a solution of $10 \mathrm{mg}$ of lipids previously dissolved in $500 \mu \mathrm{L}$ of deuterated chloroform $\left(\mathrm{CDCl}_{3}\right)$ with tetramethylsilane (TMS) [25]. ${ }^{1} \mathrm{H}-\mathrm{NMR}$ spectra were recorded using $90^{\circ}$ pulse sequence at $25^{\circ} \mathrm{C}$, acquisition time of $8.19 \mathrm{~s}$, spectral window width of $9.9955 \mathrm{~Hz}, 64 \mathrm{k}$, relaxation delay of $40 \mathrm{~s}$ ( 5 times $\mathrm{T}_{1}$ ), and 56 scans. ${ }^{1} \mathrm{H}-\mathrm{NMR}$ data were assigned in accordance with the previously reported NMR data for lipids [26].

\subsection{Data Processing}

${ }^{1} \mathrm{H}-\mathrm{NMR}(600 \mathrm{MHz})$ spectra for statistical and quantitative analyses were first processed using the TopSpin software (Bruker Corp.). Free induction decays were multiplied by a $0.3 \mathrm{~Hz}$ exponential multiplication function prior to Fourier transformation; the tetramethylsilane (TMS) signal was calibrated at $\delta 0.00$, and only a zero-order phase correction was allowed.

For statistical analysis of spectra, the binning of 0.04 ppm was applied to spectral data using MestreNova software, and spectra were transformed into a data matrix. The MetaboAnalyst 3.0 platform (http:/ / www.metaboanalyst.ca/faces/home.xhtml accessed on 1 December 2020) was used for principal component analysis (PCA) and partial least squares discriminant analysis (PLS-DA). No data filtering, no sample normalization, and Pareto scaling (mean-centered and divided by the square root of the standard deviation of each variable) were used in data preprocessing. Leave-one-out cross-validation (LOOCV) was applied in PLS-DA. The accuracy, variable importance in projection (VIP) and clustering results shown as heatmaps (distance measure using euclidean, clustering algorithm using ward.D, view options only group aver-ages of top 15 PLS-DA VIP) were also assessed.

For quantitative purposes, specific ${ }^{1} \mathrm{H}-\mathrm{NMR}$ signals were manually integrated, and the concentrations of omega-3 (L-linolenic acid) and omega-6 (Ln-linoleic acid) type fatty acids were calculated following the method previously reported by others $[26,27]$. The concentrations of fatty acids were expressed in molar percentages according to Equations (1) and (2).

$$
\mathrm{L} n \%=100 \times \mathrm{A}_{\text {omega } 3} / 3 \times \mathrm{A}_{\mathrm{G}}
$$




$$
L \%=100 \times 2 \times \mathrm{A}_{\text {omega }} 6 / 3 \times \mathrm{A}_{\mathrm{G}}
$$

in which $\mathrm{A}_{\text {omega-3 }}$ and $\mathrm{A}_{\text {omega- } 6}$ are the areas of the bis-allylic proton peaks for omega- 3 and omega- 6 fatty acids, respectively, and $A_{G}$ is the area of the proton peaks of glyceryl groups; L refers to omega-3, linolenic acid, and Ln refers to omega-6, linoleic acid.

For statistical analysis of the ratio of omega-3/omega-6, data analyses were performed using the GraphPad Prism version 7.0 for Windows (GraphPad Software Corp., La Jolla, CA, USA). Standard parametric (Student's t-test and one-way Analysis of variance, ANOVA) tests were applied accordingly to variables type and distribution, with post-hoc test Dunnett's for multiple comparisons. All distribution was checked using a Shapiro-Wilk test. All results are expressed as the value of mean \pm standard deviation (SD). The significance threshold was considered at $p \leq 0.05$.

\section{Results}

\subsection{Identification of Lipids}

${ }^{1} \mathrm{H}-\mathrm{NMR}$ data of serum lipids (Table 1 ) were assigned according to the peak numbers (1-25), as indicated in Figure S1 (Supplementary Information). Chemical shifts, peak multiplicity, and coupling constants for the 1-25 compounds were checked against databases and lipids NMR libraries. Lipids from the animal serum samples showed peaks of cholesterol, saturated fatty acids, unsaturated fatty acids, i.e., omega- 3 and omega- 6 fatty acids, phosphocholines, cardiolipins, and sphingomyelines. Additionally, glycerol esters, glycerolipids (triacylglycerols), glycerophospholipids, and saccharolipids were identified in lipid samples of drug-naïve and treated animals, receiving acute administration of psychostimulants or treated for 30 days with typical or atypical antipsychotics. It is worth mentioning that the lipids identified in the present study are in agreement with the previously described downregulation of phosphatidylcholine [10,28,29], and upregulation of triacylglycerols $[30,31]$ in SCZ patients compared with healthy control volunteers. In addition, low levels of polyunsaturated fatty acids phospholipid content, specifically in phosphatidylcholine and phosphatidylethanolamine, were reported in first-episode psychosis of SCZ [32,33].

Table 1. Rat serum ${ }^{1} \mathrm{H}-\mathrm{NMR}$ spectral assignments. The NMR peaks were numbered as illustrated in Figure S1 (Supplementary Information). Legend: ${ }^{a}$ omega- $6,{ }^{b}$ omega-3, and ${ }^{c}$ glycerol (see Equations (1) and (2) in Methods Section).

\begin{tabular}{|c|c|c|}
\hline Peak & Chemical Shift (ppm) & Assignment \\
\hline 1 & $0.58-0.70$ & Terminal methyl group in cholesterol $-\mathrm{CH}_{3}$ \\
\hline 2 & $0.75-1.00$ & $-\mathrm{CH}_{3}$ protons of saturated, oleic and linoleic acyls (omega-6) \\
\hline 3 & $0.93-1.02$ & $-\mathrm{CH}_{3}$ protons of linolenyl chain (omega-3) \\
\hline 4 & $1.20-1.50$ & Methylene protons of aliphatic chains $-\left(\mathrm{CH}_{2}\right)_{n}$ \\
\hline 5 & $1.50-1.75$ & $\beta-$ methylene protons of the carbonyl $-\mathrm{OC}(\mathrm{O})-\mathrm{CH}_{2}-\mathrm{CH}_{2-}$ \\
\hline 6 & $1.95-2.10$ & Methylene protons in the $\alpha$-position of double bonds $-\mathrm{CH}_{2}-\mathrm{CH}=\mathrm{CH}-$ \\
\hline 7 & $2.20-2.50$ & Methylene protons in the carbonyl $\alpha$-position $-\mathrm{OC}(\mathrm{O})-\mathrm{CH}_{2-}^{-}$ \\
\hline 8 & $2.70-2.84$ & $\mathrm{CH}_{2}$-bis-allyllic protons of polyunsaturated fatty acid (PUFA) chains \\
\hline 9 & $2.80-2.90^{\mathrm{a}}$ & Divinyl methylene protons $=\mathrm{HC}-\mathrm{CH}_{2}-\mathrm{CH}=$ of omega- 6 including linoleyl chain \\
\hline 10 & $2.79^{\mathrm{b}}$ & Divinyl methylene protons $=\mathrm{HC}-\mathrm{CH}_{2}-\mathrm{CH}=$ of omega- 3 including linolenyl chain \\
\hline 11 & $3.10-3.20$ & Methylene protons $\alpha$ to the heteroatom $-\mathrm{CH}_{2}-\mathrm{OH}$ \\
\hline 12 & $3.20-3.40$ & Methyl protons of charged nitrogen $-{ }^{+} \mathrm{N}\left(\mathrm{CH}_{3}\right)_{3}$ \\
\hline 13 & $3.40-3.60$ & Heteroatom proton $-\mathrm{OH}$ \\
\hline 14 & $3.44-3.59$ & $\mathrm{CH}$ of cholesterol relative to the $\mathrm{C}-3$ proton \\
\hline 15 & $3.50-3.85$ & Methylene protons $\alpha$ to a charged nitrogen $\mathrm{CH}_{2}-\mathrm{N}^{+}\left(\mathrm{CH}_{3}\right)_{3}$ \\
\hline 16 & $3.65-3.75$ & Hexoses protons on $\alpha$-carbon to the heteroatom \\
\hline 17 & 3.88 & Methine proton at C-4 of galactose \\
\hline 18 & $4.00-4.30$ & Protons on $\alpha$-carbon to the heteroatom \\
\hline 19 & $4.10-4.40$ & Protons on $\alpha$-carbon to the heteroatom $(\mathrm{OH})$ and $\beta$ to the amine $-\mathrm{O}-\mathrm{CH}_{2}-\mathrm{CH}_{2}-\mathrm{N}^{+}\left(\mathrm{CH}_{3}\right)_{3}$ \\
\hline 20 & $3.90-4.40$ & Methylene protons $\alpha$ to the heteroatom in phosphorus $\mathrm{CH}_{2}-\mathrm{O}-\mathrm{P}$ \\
\hline 21 & $4.10-4.30^{\mathrm{c}}$ & Sn-1 and Sn-3 protons of glycerol $-\mathrm{CH}_{2}-\mathrm{OC}(\mathrm{O}) \mathrm{R}$ \\
\hline 22 & 5.00 & Anomeric carbon protons of galactose \\
\hline 23 & $5.20-5.40$ & Amine protons $-\mathrm{HN}\left(\mathrm{CH}_{3}\right)_{2}$ \\
\hline 24 & $5.25-5.50$ & $\mathrm{Sn}-2$ protons of glycerol $>\mathrm{CH}-\mathrm{O}-\mathrm{C}(\mathrm{O}) \mathrm{R}$ \\
\hline 25 & $5.27-5.38$ & Protons of double bonds with conformation $\mathrm{Z}-\mathrm{CH}=\mathrm{HC}-$ \\
\hline
\end{tabular}




\subsection{Comparison of Lipids among Drug-Naïve NWR and SHR Animals, and NWR Receiving Psychostimulants}

Blood serum lipidomes of drug-naïve NWR animals were significantly different compared to drug-naïve SHR or NWR under psychostimulants effects, as presented in Figure 1. In fact, the lipids isolated from drug-naïve NWR and SHR animals were different from each other, and formed distinct groups (Figure 1A, Supplementary Information Table S1). The drug-naïve NWR lipids showed to be richer in unsaturated fatty acids (UFA), cholesterol (chol), phospholipids (PL)-saccharolipids, and choline glycerophospholipids (ChoGpl) (Figure 1C). On the other hand, the serum lipids in SHR showed different patterns with high quantities of PUFA and fatty acids in general (Figure 1C). In addition, the drugnaïve SHR strain presented lower amounts of PL compared with drug-naïve NWR, but with increased amounts of PUFA (Supplementary Information Figure S2). Further investigation may clarify if omega-3 PUFA works in compensation of phospholipids loss, as previously described by others [26,27]. The main observation is that the amounts of phospholipids are stable in the SCZ animal model (SHR), but differences in the chemical structures of these phospholipids, as the ratio between omega- 3 and omega- 6 , could be crucial for the disease and treatments, as we will further discuss.

The lipids from drug-naïve NWR animals suffered alterations under the effects of psychoactive drugs, and they were exposed to psychostimulants (AMPH or LSDX) at

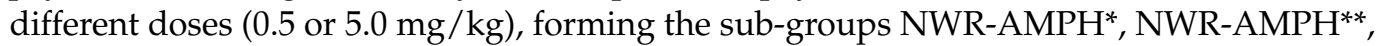
NWR-LSDX ${ }^{*}$, and NWR-LSDX** (Figure 1B,D). Cross-validation of the obtained model is presented in Supplementary Information (Table S2). Curiously, serum lipids from the AMPH and LSDX were more similar when the dose dependence was analyzed, and lower doses of psychostimulants determined different effects on NWR lipids compared to higher doses (Figure 1D). However, similarly to the findings for the differences between drugnaïve NWR vs. SHR strains, the ${ }^{1} \mathrm{H}-\mathrm{NMR}$ signals representing the phospholipids (PL) were less intense in NWR animals receiving AMPH or LSDX compared with control drug-naïve NWR. Additionally, NWR under psychostimulant effects presented higher levels of PUFA. The evaluation of omega- 3 and omega- 6 concentrations allowed calculating the omega- 6 to omega-3 ratio (Table 2). Excessive amounts of omega-6 polyunsaturated fatty acids (PUFA), and high omega-6/omega-3 ratio are both often associated with eicosanoids production in many diseases [34].

The animals receiving LSDX presented the highest concentrations of omega- 6 among all studied groups, although the omega-6/omega-3 ratio was not different from NWR receiving AMPH. Moreover, NWR animals receiving psychostimulants showed a remarkable different blood serum lipidome patterns compared with untreated drug-naïve NWR, with a dose-independent decrease in omega-3, as observed for 10-fold different doses of psychostimulants $(0.5$ and $5.0 \mathrm{mg} / \mathrm{kg})$.

It is important to point that the decrease of omega- 3 and of omega- 6 acids were statistically significant ( $p=0.0019$ and $p=0.0002$, respectively), as well as the omega-6/omega-3 ratio $(p=0.0042)$, compared with drug-naïve SHR or drug-naïve NWR. However, only omega-3 (decrease) and omega-6/omega-3 (increase) ratio were significantly changed $(p<0.0001)$ in NWR after administration of psychostimulants. Thus, we suggest that the omega-3 acid levels could be used as a parameter to evaluate the effects of psychostimulant drugs on lipid changes in animal models. 
A)

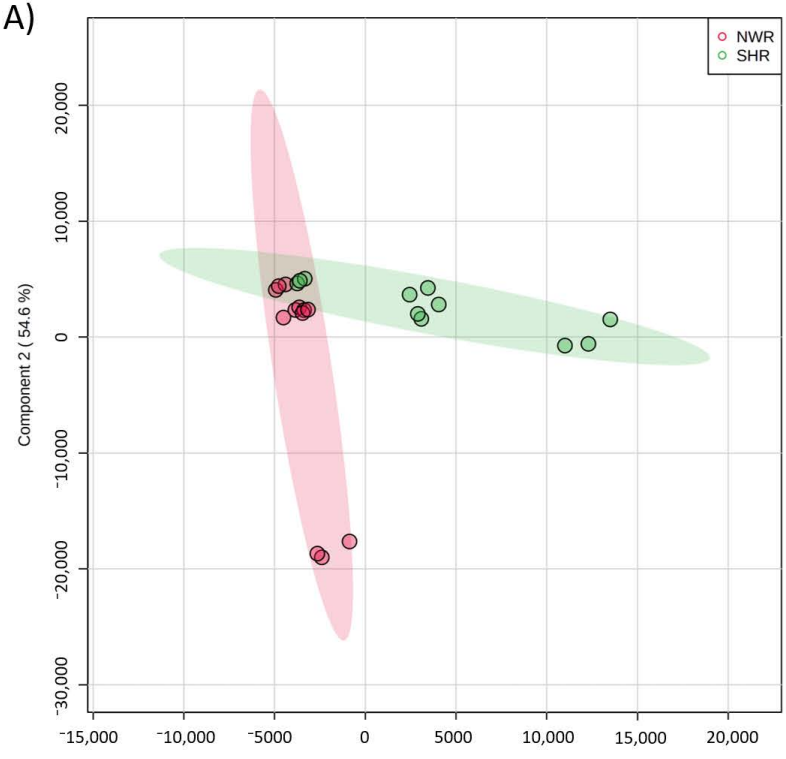

C)

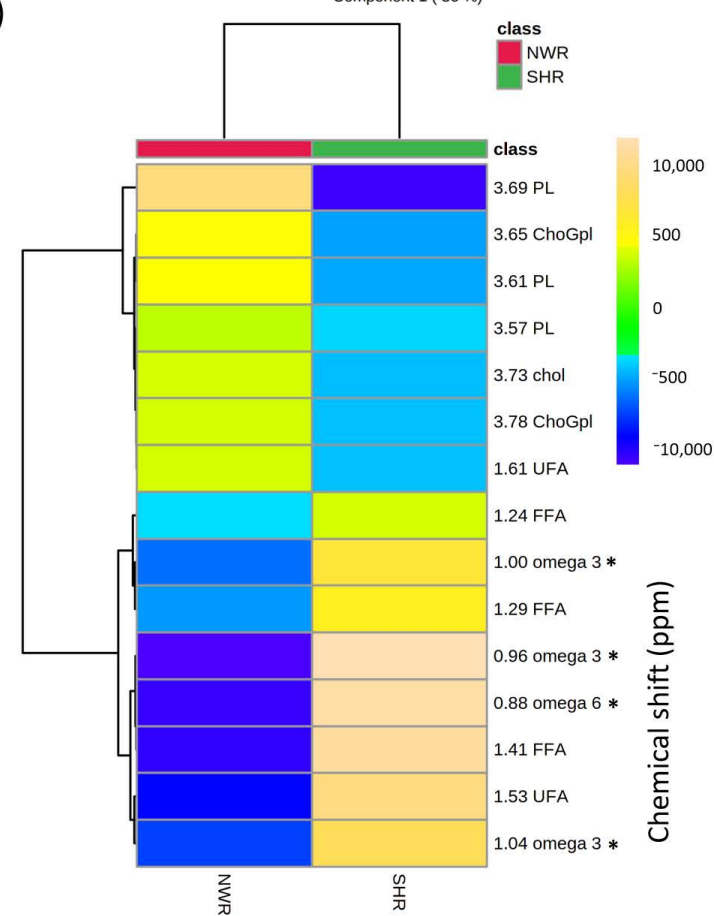

B)

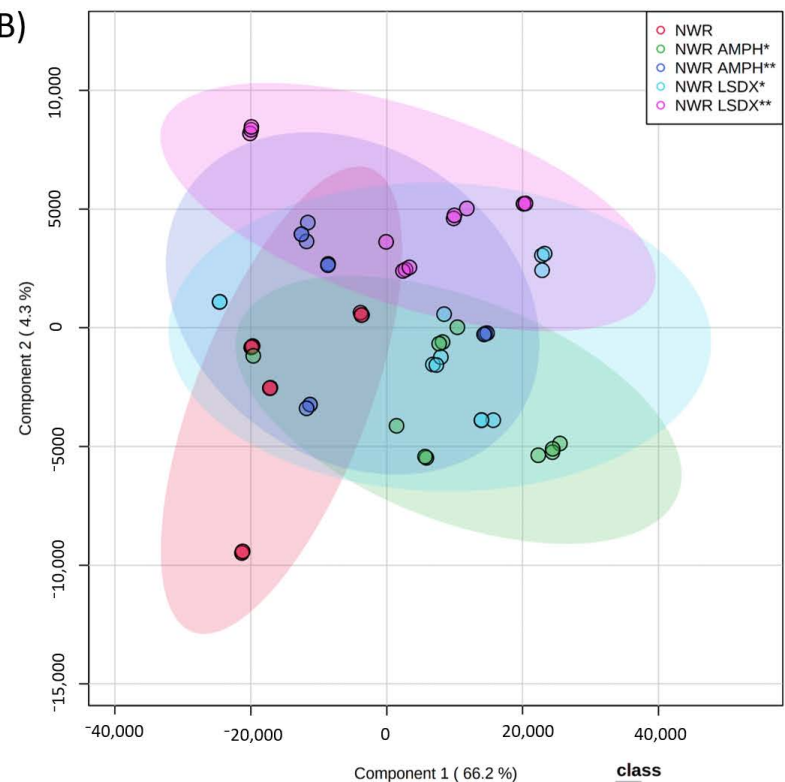

D)

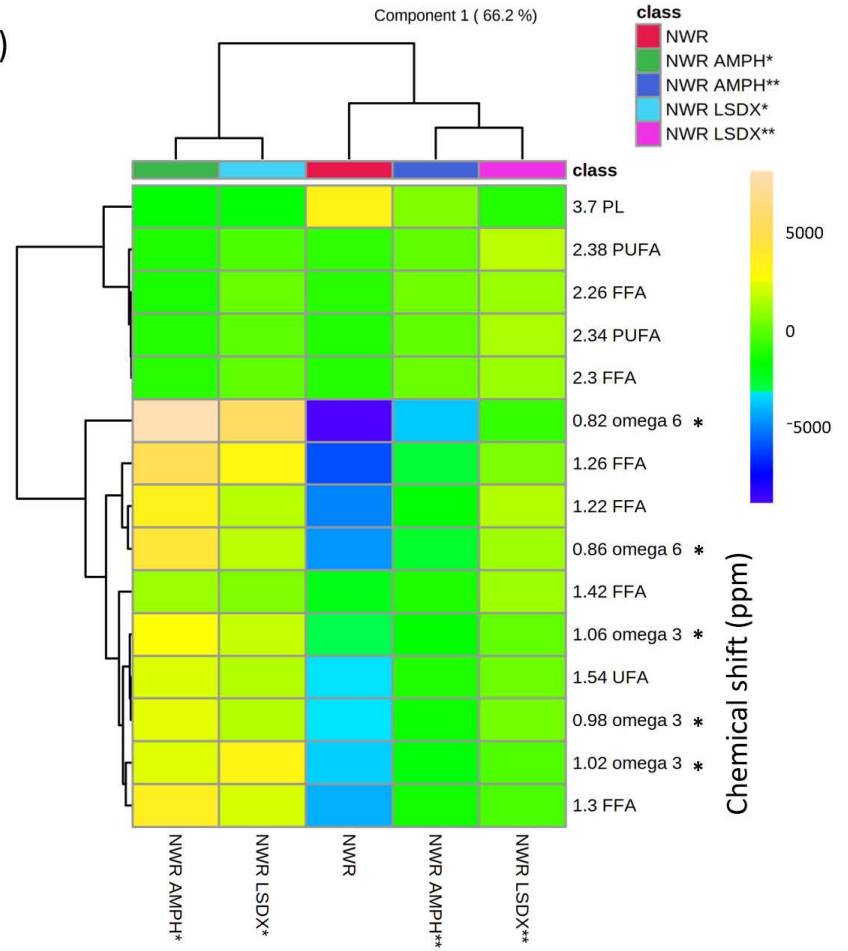

Figure 1. Partial least squares discriminant analysis (PLS-DA) on animal serum lipids ${ }^{1} \mathrm{H}-\mathrm{NMR}$ data: (A) schizophrenia (SCZ) model (spontaneously hypertensive rat, SHR) vs. control (normotensive Wistar rat, NWR) score plot in PC 1 and PC 2. A total of 23 spectra were used for PLS-DA analysis of SHR against NWR, being four samples of each treatment in triplicate excluding one outlier (SHR group). (B) 3D score plot for evaluation in NWR of the effects on lipids of psychostimulants amphetamine (AMPH) or lisdexamfetamine (LSDX) with doses of $\left(^{*}\right) 0.5 \mathrm{mg} / \mathrm{kg}$ and $\left({ }^{* *}\right) 5.0 \mathrm{mg} / \mathrm{kg}$. A total of 62 spectra were used for PLS-DA analysis of NWR after AMPH or LSDX administration, with five samples for each treatment (four samples for NWR), performed in triplicate, but excluding three outliers in NWR-LSDX* group, three outliers in NWR-AMPH* group, two outliers of NWR-LSDX* group, and two outliers in NWR-AMPH* group. (C) Heatmap for SHR vs. NWR shows relative concentrations of the 15 most important variables in projection (VIP). (D) Heatmap for NWR vs. AMPH or LSDX shows the relative concentrations of the fifteen variables (VIP) before and after psychostimulants administration. In (C,D), chemical shifts marked for omega $3 *$, omega $6 *$, may come from other acyl groups. PL: phospholipids, ChoGpl: choline glycerophospholipids, chol: cholesterol, FFA: free fatty acids, PUFA: polyunsaturated fatty acids, UFA: unsaturated fatty acids. 
Table 2. Changes in omega- 3 and omega- 6 acids determination using the ${ }^{1} \mathrm{H}-\mathrm{NMR}$ data from control NWR animals after the administration of psychostimulants (mean values $\pm \mathrm{SD}$ ).

\begin{tabular}{|c|c|c|c|c|}
\hline & & Omega $3(\%)$ & Omega $6(\%)$ & Omega $6 / 3$ \\
\hline \multirow{6}{*}{ Groups } & NWR & $50.16 \pm 9.04$ & $25.74 \pm 5.18$ & $0.52 \pm 0.05$ \\
\hline & SHR & $26.37 \pm 5.39$ & $7.43 \pm 1.06$ & $0.29 \pm 0.10$ \\
\hline & NWR-AMPH * & $5.41 \pm 1.56$ & $22.28 \pm 7.68$ & $4.12 \pm 1.30$ \\
\hline & NWR-AMPH ** & $6.03 \pm 2.52$ & $25.86 \pm 3.10$ & $4.66 \pm 1.25$ \\
\hline & NRW-LSDX * & $10.10 \pm 3.75$ & $43.50 \pm 17.40$ & $4.33 \pm 0.81$ \\
\hline & NRW-LSDX ** & $10.13 \pm 2.55$ & $33.65 \pm 6.05$ & $3.49 \pm 1.05$ \\
\hline \multirow{11}{*}{$p$-Values } & $\mathrm{NWR} \times \mathrm{SHR}$ & $\begin{array}{c}0.0025 \\
(t=5.24)\end{array}$ & $\begin{array}{c}0.0002 \\
(t=6.85)\end{array}$ & $\begin{array}{c}0.0042 \\
(t=4.16)\end{array}$ \\
\hline & NWR $\times$ NWR-AMPH * & $\begin{array}{c}<0.0001 \\
(t=10.90)\end{array}$ & $\begin{array}{c}0.5400 \\
(t=0.83)\end{array}$ & $\begin{array}{c}0.0003 \\
(t=6.15)\end{array}$ \\
\hline & NWR $\times$ NWR-AMPH $* *$ & $<0.0001$ & 0.9992 & $<0.0001$ \\
\hline & NWK X NVVR-AIIPH & $(t=10.51)$ & $(t=0.042)$ & $(t=7.41)$ \\
\hline & 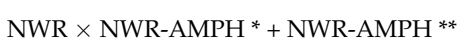 & $\begin{array}{c}<0.0001 \\
(\mathrm{~F}(2,14)=109.0)\end{array}$ & $\begin{array}{c}0.5403 \\
(\mathrm{~F}(2,14)=0.64)\end{array}$ & $\begin{array}{c}<0.0001 \\
(\mathrm{~F}(2,14)=23.26)\end{array}$ \\
\hline & NWR $\times$ NWR-LSDX* & $\begin{array}{c}<0.0001 \\
(t=9.14)\end{array}$ & $\begin{array}{c}0.0467 \\
(t=2.57)\end{array}$ & $\begin{array}{l}<0.0001 \\
(t=10.42)\end{array}$ \\
\hline & NWR $\times$ NWR-LSDX ** & $<0.0001$ & 0.4440 & $<0.0001$ \\
\hline & NVK X NVVK-LSDX & $(t=9.52)$ & $(t=2.31)$ & $(t=6.28)$ \\
\hline & NWR $\times$ NWR-LSDX * + NWR-LSDX ** & $\begin{array}{c}<0.0001 \\
(\mathrm{~F}(2-14)=7827)\end{array}$ & $\begin{array}{c}0.0749 \\
(\mathrm{~F}(2-14)=324)\end{array}$ & $\begin{array}{l}<0.0001 \\
(5-14)-3374)\end{array}$ \\
\hline & $\mathrm{SHR} \times \mathrm{NWR}-\mathrm{AMPH}^{*}+\mathrm{NWR}-\mathrm{AMPH}{ }^{* *}$ & $\begin{array}{c}<0.0001 \\
(\mathrm{~F}(2,14)=54.64)\end{array}$ & $\begin{array}{c}0.0005 \\
(\mathrm{~F}(2,14)=16.30)\end{array}$ & $\begin{array}{c}0.0002 \\
(\mathrm{~F}(2,14)=20.37)\end{array}$ \\
\hline & SHR $\times$ NWR-LSDX * + NWR-LSDX ** & $\begin{array}{c}<0.0001 \\
(\mathrm{~F}(2,14)=24.42)\end{array}$ & $\begin{array}{c}0.0016 \\
(\mathrm{~F}(2,14)=12.18)\end{array}$ & $\begin{array}{c}<0.0001 \\
(\mathrm{~F}(2,14)=29.97)\end{array}$ \\
\hline
\end{tabular}

Note: Normal Wistar rat (NWR); Spontaneously Hypertensive rat (SHR); amphetamine (AMPH) and lisdexamfetamine (LSDX) $\left({ }^{*} 0.5\right.$ and $\left.{ }^{* *} 5.0 \mathrm{mg} / \mathrm{kg}\right)$; standard deviation $(\mathrm{SD})$. Student's t-test for NWR $\times$ SHR; NWR $\times$ NWR-AMPH *; NWR $\times$ NWR-AMPH **; NWR $\times$ NWR-LSDX * and NWR $\times$ NWR-LSDX **. One-way ANOVA, post-hoc test Dunnett's for multiple comparisons for NWR $\times$ $\mathrm{NWR}_{-\mathrm{AMPH}}^{*} \times \mathrm{NWR} \times \mathrm{AMPH}^{* *}, \mathrm{NWR} \times \mathrm{NWR}-\mathrm{LSDX}^{*} \times \mathrm{NWR} \times \mathrm{LSDX}^{* *}, \mathrm{SHR} \times \mathrm{NWR}-\mathrm{AMPH} * \times \mathrm{NWR} \times \mathrm{AMPH} * *$ and SHR $\times$ NWR-LSDX * $\times$ NWR $\times$ LSDX $* *$. Values are significantly different for $p \leq 0.05(\mathrm{~N}=5)$.

\subsection{Influences of Antipsychotics HAL and CLZ on Lipids in SHR and NWR Animals}

The PLS-DA based on the ${ }^{1} \mathrm{H}-\mathrm{NMR}$ spectra of lipids extracted from the serum of animals treated with typical HAL or atypical CLZ antipsychotics showed significant differences in lipids composition in antipsychotics-treated SHR compared with control SHR receiving vehicle (Figure 2A,C, and Supplementary Information-Table S3, and Figure S3A,B). The atypical antipsychotic CLZ modified serum lipids to a greater extent relative to the effects determined by the treatment with HAL (Figure 2A), with greater variations in the most chemical shifts (Figure 2C, VIP) compared with the effects determined by the treatment of SHR animals with HAL. Additionally, increases in 4/15, and decreases in 11/15 lipids levels after treatment with CLZ (see dendogram in Figure 2C) were among the most prominent effects. Analysis in the variations in PUFA and omega-3 chemical shifts (Figure S3B) showed important decreases with CLZ treatment. It is also important to point to omega-3, and phospholipids (PL) levels decrease in SHR strain, following the treatment with CLZ (Figure 2C), in addition to the decrease in omega-6 (0.84 ppm), and increase in fatty acids (1.24 ppm). However, an increment in membrane omega-6 fatty acids in SCZ patients after treatment with CLZ was described by others [35].

Moreover, CLZ treatment showed the greatest lipids variations for comparisons between antipsychotic-treated and control NWR animals receiving vehicle (Figure 2B,D, Supplementary Information Table S4). Treatment with HAL slightly increased PUFA and phospholipids (PL) in NWR. In addition to the decreases in PUFAs levels (particularly omega-6), and phospholipids levels observed after the treatment with CLZ, choline glycerophospholipids (ChoGpl) were also identified as an important lipid subclass of phospholipids to distinguish the effects of CLZ in NWR, as ChoGpl were also decreased by CLZ treatment (Figure 2D and Supplementary Information Figure S4D). This last effect was opposite to that observed for SHR strain treated with CLZ, as illustrated in Figure S4C, in which ChoGpl increased in SHR animals after CLZ treatment. In addition, the CLZ effect on omega-3 and omega-6 levels and their ratio in NWR strain were also observed. CLZ determined decreases in omega- 3 and omega- 6 in both NWR and SHR strains. 

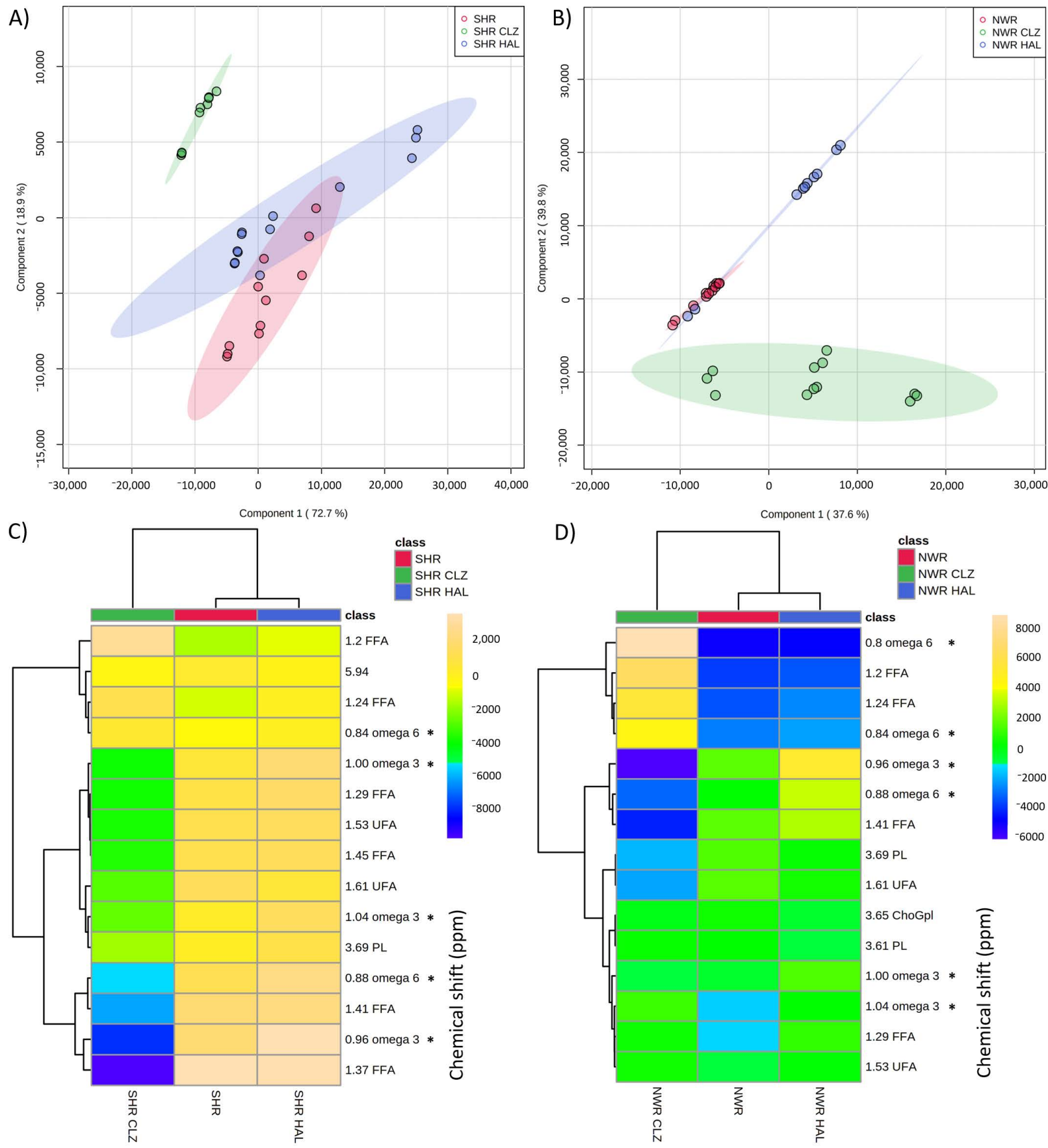

Figure 2. PLS-DA charts obtained for ${ }^{1} \mathrm{H}-\mathrm{NMR}$ of lipids isolated from drug-naïve SHR $(\mathbf{A}, \mathbf{C})$ and drug-naïve NWR animals (B,D) after the treatment with typical haloperidol (HAL) or atypical atypical clozapine (CLZ) antipsychotic drugs. SHR lipid profile changes are shown as PLS-DA scores (A) or heatmap (C) with the relative concentrations of the 15 best-ranked chemical shifts (VIP scores). NWR lipid profile changes are shown as PLS-DA scores (B) or heatmap (D) with the relative concentrations of the 15 best-ranked chemical shifts (VIP scores). A total of 34 spectra were used for PLS-DA analysis of SHR after treatment with typical HAL or atypical CLZ antipsychotic drugs, with five samples for each treatment (4 samples for SHR), performed in triplicate, but excluding one outlier of SHR, five outliers of SHR CLZ, and two outliers of SHR-HAL. A total of 34 spectra were used for PLS-DA analysis of NWR treated with typical HAL or atypical CLZ antipsychotic drugs, with five samples for each treatment (four samples for NWR), performed in triplicate, but excluding two outliers of NWR-CLZ, and five outliers of NWR-HAL. In (C,D), chemical shifts marked for omega $3 *$, omega 6 , may come from other unsaturated acyl groups. PL: phospholipids, ChoGpl: choline glycerophospholipids, chol: cholesterol, FFA: free fatty acids, PUFA: polyunsaturated fatty acids, UFA: unsaturated fatty acids. 
The treatment with the atypical antipsychotic CLZ modified the blood serum lipid profiles in SHR animals by causing a different trend compared with what was observed in NWR. Changes in omega-3 and omega- 6 determined by the treatment with (typical or atypical) antipsychotic drugs in NWR and SHR (mean values \pm SD) are shown in Table 3.

Table 3. Changes in omega-3 and omega- 6 determined by ${ }^{1} \mathrm{H}-\mathrm{NMR}$ in NWR and SHR after the treatment with (typical or atypical) antipsychotic drugs (mean values $\pm \mathrm{SD}$ ).

\begin{tabular}{|c|c|c|c|c|}
\hline & & Omega-3 (\%) & Omega-6 (\%) & Omega $6 / 3$ \\
\hline \multirow{6}{*}{ Groups } & NWR & $50.16 \pm 9.04$ & $25.74 \pm 5.18$ & $0.52 \pm 0.05$ \\
\hline & SHR & $26.37 \pm 5.39$ & $7.43 \pm 1.06$ & $0.29 \pm 0.10$ \\
\hline & NWR-HAL & $0.75 \pm 0.26$ & $2.15 \pm 0.54$ & $3.02 \pm 0.71$ \\
\hline & SHR-HAL & $0.92 \pm 0.09$ & $2.96 \pm 0.77$ & $3.16 \pm 0.62$ \\
\hline & NWR-CLZ & $0.90 \pm 0.44$ & $2.69 \pm 1.48$ & $2.87 \pm 1.42$ \\
\hline & SHR-CLZ & $1.00 \pm 0.57$ & $1.07 \pm 0.50$ & $2.60 \pm 2.08$ \\
\hline \multirow{7}{*}{$p$-Values } & $\mathrm{NWR} \times \mathrm{SHR}$ & $\begin{array}{c}0.0019 \\
(t=5.24)\end{array}$ & $\begin{array}{c}0.0002 \\
(t=7.83)\end{array}$ & $\begin{array}{c}0.0042 \\
(t=3.74)\end{array}$ \\
\hline & NWR $\times$ NWR-HAL & $\begin{array}{c}<0.0001 \\
(t=14.05)\end{array}$ & $\begin{array}{c}<0.0001 \\
(t=11.48)\end{array}$ & $\begin{array}{c}0.0037 \\
(t=6.89)\end{array}$ \\
\hline & NWR $\times$ NWR-CLZ & $\begin{array}{c}<0.0001 \\
(t=14.03)\end{array}$ & $\begin{array}{c}<0.0001 \\
(t=10.71)\end{array}$ & $\begin{array}{c}0.0163 \\
(t=3.31)\end{array}$ \\
\hline & NWR $\times$ NWR-HAL + NWR-CLZ & $\begin{array}{c}<0.0001 \\
(\mathrm{~F}(2,14)=195.4)\end{array}$ & $\begin{array}{c}<0.0001 \\
(\mathrm{~F}(2,14)=114.4)\end{array}$ & $\begin{array}{c}0.0708 \\
(\mathrm{~F}(2,14)=3.41)\end{array}$ \\
\hline & $\mathrm{SHR} \times \mathrm{SHR}-\mathrm{HAL}$ & $\begin{array}{c}<0.0001 \\
(t=10.73)\end{array}$ & $\begin{array}{c}0.0002 \\
(t=7.27)\end{array}$ & $\begin{array}{c}0.0110 \\
(t=8.92)\end{array}$ \\
\hline & $\mathrm{SHR} \times \mathrm{SHR}-\mathrm{CLZ}$ & $\begin{array}{c}<0.0001 \\
(t=10.68)\end{array}$ & $\begin{array}{c}<0.0001 \\
(t=10.75)\end{array}$ & $\begin{array}{c}0.0456 \\
(t=2.66)\end{array}$ \\
\hline & $\mathrm{SHR} \times \mathrm{SHR}-\mathrm{HAL}+\mathrm{SHR}-\mathrm{CLZ}$ & $\begin{array}{c}<0.0001 \\
(\mathrm{~F}(2,14)=114.6)\end{array}$ & $\begin{array}{c}<0.0001 \\
(\mathrm{~F}(2,14)=64.81)\end{array}$ & $\begin{array}{c}0.0143 \\
(F(2,14)=6.69)\end{array}$ \\
\hline
\end{tabular}

Note: Normal Wistar rats (NWR); Spontaneously Hypertensive rats (SHR); haloperidol (HAL); clozapine (CLZ); standard deviation (SD). Student's $t$-test for NWR $\times$ SHR; NWR $\times$ NWR-HAL; NWR $\times$ NWR-CLZ; SHR $\times$ SHR-HAL and SHR $\times$ SHR-CLZ, and One-way ANOVA, post-hoc test Dunnett's for multiple comparisons for NWR $\times$ NWR-HAL $\times$ NWR-CLZ and SHR $\times$ SHR-HAL $\times$ SHR-CLZ. Values are significantly different for $p \leq 0.05(\mathrm{~N}=5)$.

The levels of omega-3 and omega- 6 were both significantly different between NWR and SHR lipidomes $(p=0.0019$ and $p=0.0002$, respectively). The levels of omega-3 decreased with the treatment with antipsychotic drugs (HAL or CLZ) $(p<0.0001)$, while the omega-6/omega-3 ratios were significantly increased in SHR and NWR after the treatment with HAL or CLZ.

The levels of omega-3, omega-6, and phospholipids may suggest that these important PUFAs were incorporated into ChoGpl, which play important roles in cell membranes. ChoGpl were decreased in NWR treated with CLZ, and were increased in SHR treated with CLZ, and ChoGpl levels in SHR after the treatment with this atypical antipsychotic were closer to those in control NWR receiving vehicle (Supplementary Information Figure S4).

The differences in the effects of typical and atypical antipsychotics were evidenced by the greater lipid changes observed for the treatment with CLZ compared with HAL, as one could expect based on the well-known general pharmacological superiority of CLZ compared to typical antipsychotics, as reported by many [36-38]. In addition, CLZ is approximately $30 \%$ more effective in controlling schizophrenic episodes in treatmentresistant patients than other antipsychotic drugs [1]. However, both typical HAL and atypical CLZ antipsychotic drugs equally induced changes in omega-6/omega-3 values in both NWR and SHR strains (Table 3).

\section{Discussion}

The presence of cholesterol in the serum samples from SCZ-animal model studied here could be associated with the accumulation of cholesterol in the nigrostriatal pathway, which was suggested to contribute to the dopaminergic neurodegeneration in mice brain [39], or to induce cognitive dysfunctions in rats [40]. Additionally, dysfunctions in brain cholesterol homeostasis have been extensively correlated to several other brain disorders, such as autism, Alzheimer's, Parkinson's and Huntington's diseases [35,41-43]. 
In addition, polyunsaturated fatty acids (PUFAs) are reported to be significantly correlated with the negative SCZ symptoms, and their incorporation into plasma membrane phospholipids can remodel the molecular organization of cholesterol-enriched lipid microdomains $[44,45]$. Some changes in the composition of membrane phospholipids could be associated with SCZ, since the abnormal composition of esterified fatty acids, such as phospholipids, has been reported in plasma, red blood cells, fibroblasts and in post-mortem prefrontal cerebral cortical tissues of SCZ patients. Then, the storage and release of neurotransmitters may also be affected by the changes in the lipid composition of neuronal cell membranes [9-11,28,30,46-49]. Interestingly, omega-3 PUFA deficiency in blood was reported to be a trigger of the effects on the dopamine system, and this blood PUFA deficiency was also associated with SCZ [50]. In addition, omega-3 PUFA deficiency was associated with cognitive impairment, which directly impacts the social functioning in patients with SCZ [51]. Thus, the decreases of phospholipids in SHR animals, and also in NWR animals after receiving psychostimulants (such as AMPH and LSDX) possibly validate the SCZ animal model adopted here. However, the decreased amounts of omega-3 and omega -6 fatty acids in SCZ animal models compared with control NWR strain could point out to possible compensation mechanisms [52].

The differences between animals receiving AMPH or LSDX, including the highest concentrations of omega- 6 observed after LSDX administration, could be explained by the fact that psychostimulant effects of AMPH are immediate, while LSDX is a prodrug of $\mathrm{AMPH}$ and requires its conversion to the active metabolite AMPH, explaining the differences in their action onset [53]. However, despite the same mechanisms of action of these psychostimulants, they also differ in the determination of blood pressure increases, which is more evident for AMPH compared with LSDX, even when used at same doses [1], but which was not correlated with the changes in biochemical biomarkers or in SCZ-like animal behavior [13-15,54]. Taking this into account, two different doses of psychostimulants were evaluated here, as they could potentially lead to different effects on lipids metabolism, as we, in fact, observed here.

The linoleic (omega-6) and alpha-linolenic (omega-3) fatty acids are two essential PUFAs that must come from diet, and they are also constituents of neuronal membrane phospholipids with a reported contribution to proliferation and differentiation of neural stem cells [55]. Moreover, the importance of omega-3 fatty acids for the structure and function of neuronal membranes is also well-known [56,57]. Therefore, the increased levels of omega-3 in drug-naïve control NWR compared to drug-naïve SHR strain may point out a possible "healthier" cerebral condition in NWR animals. There are some recognized differences in susceptibility to psychostimulant-induced neurotoxicity [58], as for instance, the psychostimulant-induced release of dopamine into the extracellular space, from the newly synthesized pool of transmitter, which plays an essential role in drug-induced neurotoxicity [59]. And this may possibly explain the differences observed for the effects of different doses of AMPH or LSDX evaluated here. Furthermore, lipid metabolism in SCZ might be related not just to the aberration of neural pathways, but also to disturbances in the tryptophan-kynurenine metabolic pathway [6-8], which may warrant future investigation.

Again, since phospholipids are essential constituents of the brain cell membranes, their metabolism might be of great importance in SCZ, as the structural integrity and functional properties of neurons are strongly affected in SCZ patients $[9,10]$. Moreover, insufficient uptake and biosynthesis or even excessive breakdown of phospholipids from the brain membrane were all hypothesized to be associated with SCZ and dysfunctional synapses [9-11]. Thus, the greater levels of phospholipids in the SCZ animal model treated with antipsychotics HAL or CLZ might be indicative of a possible de novo stimulated synthesis of phospholipids aiming to supply the deficiency of these phospholipids.

Ward and collaborators suggested that the exposure to atypical antipsychotics may not differentiate metabolic phenotypes of patients with SCZ [36], in spite of the several other reports suggesting the neurotoxicity of antipsychotics [37-39,60]. In addition, we also 
need to consider that these antipsychotics could possibly inhibit the intracellular traffic of lipids [61]. Therefore, in general, we can suggest that typical and atypical antipsychotic drugs had opposite effects on lipid changes, as both HAL and CLZ increased the relative concentrations of omega-6/omega-3 ratio in SHR, although also increasing the levels of ChoGpl.

Considering the well-known importance of omega-3 fatty acids for the structure and function of neuronal membranes [56,57], the decreases in omega-3 and phospholipids in SHR after the treatment with HAL may suggest a possible negative effect of typical antipsychotics in the lipid profile of SCZ patients. However, the increases in omega6/omega-3 ratios, and the decreases of omega-3 and phospholipids (mainly ChoGpl) levels after the treatment with CLZ, may both suggest a good correlation with the recognized general pharmacological superiority of CLZ compared to typical antipsychotics [36-38]. Moreover, more evident changes in lipid profiles in both rat strains were observed for the treatments with the atypical antipsychotic CLZ compared with typical antipsychotic HAL.

\section{Conclusions}

Taken together, the results presented here support a concept of altered lipids metabolism in a validated animal model for schizophrenia (SCZ), namely SHR. Acute administration of psychostimulants in control animal strain (NWR) showed similar lipid composition alterations as observed in SHR serum samples, and as also observed in the first episode of psychosis or SCZ patients. In addition, the SCZ-like serum lipids profile was reversed more efficiently by the long-term treatment with the atypical antipsychotic drug clozapine (CLZ), relative to the typical antipsychotic haloperidol (HAL). Considering that CLZ is approximately 30\% more effective in controlling schizophrenic episodes in treatmentresistant patients than other antipsychotic drugs, it would be possible to hypothesize that CLZ effects on SCZ symptoms could also benefit from the serum lipids alterations as described herein. Moreover, the treatment with the HAL did not determine significant turnover in serum lipids in the present animal model for SCZ, as the lipids remained almost unaltered even after long-term treatment with this typical antipsychotic drug. Therefore, although metabolic syndrome has been more often correlated with the long-term treatment with atypical antipsychotic drug CLZ, it seems to be a better option to minimize the alteration in serum lipids in SCZ patients.

Supplementary Materials: The following are available online at https:/ / www.mdpi.com/2227-905 9/9/3/235/s1.

Author Contributions: Conceptualization, L.T. and M.A.F.H.; methodology, B.S.B.C., J.V.N., R.W.R., D.S.; data treatment, B.S.B.C., J.V.N., D.S., T.B.B.C.C.; writing-original draft preparation, B.S.B.C., J.V.N., D.S., T.B.B.C.C.; writing—review and editing, L.T., M.A.F.H.; supervision, L.T., M.A.F.H. All authors have read and agreed to the published version of the manuscript.

Funding: Mirian A. F. Hayashi is supported by FAPESP (Grants 2017/02413-1, 2019/13112-8), CNPq (477760/2010-4; 557753/2010-4; 508113/2010-5; 311815/2012-0; 475739/2013-2; 309337/2016-0), and National Institute for Translational Medicine (INCT-TM). João V. Nani is a recipient of a fellowship from FAPESP (2019/09207-3). Ljubica Tasic received FAPESP Grants (2014/50867-3, 2018/24069-3), thanks to CNPq, INCTBio, and *grant \#2021/01051-4 from FAPESP. This study was financed in part by the Coordenação de Aperfeiçoamento de Pessoal de Nível Superior (CAPES), Brazil-Finance Code 001. We thank the support from FAPESP, grant number 2021/01051-4.

Institutional Review Board Statement: The study was conducted according to the guidelines of the Committee on Care and Use of Laboratory Animal Resources, National Research Council, USA. This study was approved by the Ethical Committee of the Universidade Federal de São Pau-lo (UNIFESP/EPM), identification CEUA No 7290170315, approved on 15 March 2015.

Informed Consent Statement: Not applicable.

Acknowledgments: We thank the executive secretary Rosemary Alves de Oliveira for the great administrative support and Marcela Nering for the extraordinary technical assistance. 
Conflicts of Interest: The authors declare no conflict of interest.

$\begin{array}{ll}\text { Abbreviations } \\ { }^{1} \text { H NMR } & \text { Proton NMR } \\ \text { AMPH } & \text { Amphetamine } \\ \text { ANOVA } & \text { Analysis of variance } \\ \text { ChoGpl } & \text { Choline glycerophospholipids } \\ \text { Chol } & \text { Cholesterol } \\ \text { CLZ } & \text { Clozapine } \\ \text { FFA } & \text { Free fatty acids } \\ \text { HAL } & \text { Haloperidol } \\ \text { LOOCV } & \text { Leave-one-out cross-validation } \\ \text { LSDX } & \text { Lisdexamfetamine } \\ \text { MD } & \text { Mental disorder } \\ \text { NMR } & \text { Nuclear magnetic resonance } \\ \text { NWR } & \text { Normotensive Wistar rat } \\ \text { PCA } & \text { Principal component analysis } \\ \text { PL } & \text { Phospholipids } \\ \text { PLS-DA } & \text { Partial least squares discriminant analysis } \\ \text { PUFA } & \text { Polyunsaturated fatty acid } \\ \text { SCZ } & \text { Schizophrenia } \\ \text { SD } & \text { Standard deviation } \\ \text { SHR } & \text { Spontaneously hypertensive rat } \\ \text { UFA } & \text { Unsaturated fatty acids } \\ \text { VIP } & \text { Variable importance in projection }\end{array}$

\section{References}

1. Patel, K.R.; Cherian, J.; Gohil, K.; Atkinson, D. Schizophrenia: Overview and treatment options. Pharm. Ther. 2014, $39,638-645$.

2. Murray, R.M.; Lappin, J.; Di Forti, M. Schizophrenia: From developmental deviance to dopamine dysregulation. Eur. Neuropsychopharmacol. 2008, 18, S129-S134. [CrossRef] [PubMed]

3. Owen, M.J.; Sawa, A.; Mortensen, P.B. Schizophrenia. Lancet 2016, 388, 86-97. [CrossRef]

4. Rodríguez, B.; Nani, J.V.; Almeida, P.G.C.; Brietzke, E.; Lee, R.S.; Hayashi, M.A.F. Neuropeptides and oligopeptidases in schizophrenia. Neurosci. Biobehav. Rev. 2020, 108, 679-693. [CrossRef]

5. Nucifora, F.C.; Woznica, E.; Lee, B.J.; Cascella, N.; Sawa, A. Treatment resistant schizophrenia: Clinical, biological, and therapeutic perspectives. Neurobiol. Dis. 2019, 131, 104257. [CrossRef] [PubMed]

6. Ulivieri, M.; Wierońska, J.M.; Lionetto, L.; Martinello, K.; Cieslik, P.; Chocyk, A.; Curto, M.; Di Menna, L.; Iacovelli, L.; Traficante, A.; et al. The trace kynurenine, cinnabarinic acid, displays potent antipsychotic-like activity in mice and its levels are reduced in the prefrontal cortex of individuals affected by schizophrenia. Schizophr. Bull. 2020, 46, 1471-1481. [CrossRef] [PubMed]

7. Koola, M.M. Alpha7 nicotinic-N-methyl-D-aspartate hypothesis in the treatment of schizophrenia and beyond. Hum. Psychopharmacol. Clin. Exp. 2021, 36, 1-16. [CrossRef]

8. Tanaka, M.; Bohár, Z.; Vécsei, L. Are kynurenines accomplices or principal villains in dementia? Maintenance of kynurenine metabolism. Molecules 2020, 25, 564. [CrossRef]

9. Ghosh, S.; Dyer, R.A.; Beasley, C.L. Evidence for altered cell membrane lipid composition in postmortem prefrontal white matter in bipolar disorder and schizophrenia. J. Psychiatr. Res. 2017, 95, 135-142. [CrossRef]

10. Wood, P.L.; Unfried, G.; Whitehead, W.; Phillipps, A.; Wood, J.A. Dysfunctional plasmalogen dynamics in the plasma and platelets of patients with schizophrenia. Schizophr. Res. 2015, 161, 506-510. [CrossRef] [PubMed]

11. Tessier, C.; Sweers, K.; Frajerman, A.; Bergaoui, H.; Ferreri, F.; Delva, C.; Lapidus, N.; Lamaziere, A.; Roiser, J.P.; De Hert, M.; et al. Membrane lipidomics in schizophrenia patients: A correlational study with clinical and cognitive manifestations. Transl. Psychiatry 2016, 6, e906. [CrossRef] [PubMed]

12. Nani, J.V.; Rodríguez, B.; Cruz, F.; Hayashi, M.A.F. Animal Models in Psychiatric Disorder Studies. In Animal Models in Medicine and Biology; Tvrdá, E., Yenisetti, S.C., Eds.; IntechOpen: London, UK, 2019; pp. 1-18.

13. Calzavara, M.B.; Medrano, W.A.; Levin, R.; Kameda, S.R.; Andersen, M.L.; Tufik, S.; Silva, R.H.; Frussa-Filho, R; Abilio, V.C. Neuroleptic drugs revert the contextual fear conditioning deficit presented by spontaneously hypertensive rats: A potential animal model of emotional context processing in schizophrenia? Schizophr. Bull. 2009, 35, 748-759.

14. Levin, R.; Calzavara, M.B.; Santos, C.M.; Medrano, W.A.; Niigaki, S.T.; Abílio, V.C. Spontaneously hypertensive Rats (SHR) present deficits in prepulse inhibition of startle specifically reverted by clozapine. Prog. Neuro-Psychopharmacol. Biol. Psychiatry 2011, 35, 1748-1752. [CrossRef] 
15. Nani, J.V.; Yonamine, C.M.; Castro Musial, D.; Dal Mas, C.; Mari, J.J.; Hayashi, M.A.F. ACE activity in blood and brain axis in an animal model for schizophrenia: Demonstration of face validity related to ACE and predictive validity in response to antipsychotics. World J. Biol. Psychiatry 2019, 21, 1-11.

16. Calzavara, M.B.; Levin, R.; Medrano, W.A.; Almeida, V.; Sampaio, A.P.F.; Barone, L.C.; Frussa-Filho, R.; Abílio, V.C. Effects of antipsychotics and amphetamine on social behaviors in spontaneously hypertensive rats. Behav. Brain Res. 2011, $225,15-22$. [CrossRef] [PubMed]

17. Gadelha, A.; Machado, M.F.M.; Yonamine, C.M.; Sato, J.R.; Juliano, M.A.; Oliveira, V.; Bressan, R.A.; Hayashi, M.A.F. Plasma Ndel1 enzyme activity is reduced in patients with schizophrenia-a potential biomarker? J. Psychiatr. Res. 2013, 47, 657-663. [CrossRef]

18. Gadelha, A.; Yonamine, C.M.; Ota, V.K.; Oliveira, V.; Sato, J.R.; Belangero, S.I.; Bressan, R.A.; Hayashi, M.A.F. ACE I/D genotyperelated increase in ACE plasma activity is a better predictor for schizophrenia diagnosis than the genotype alone. Schizophr. Res. 2015, 164, 109-114. [CrossRef] [PubMed]

19. Dal Mas, C.; Nani, J.V.; Noto, C.; Yonamine, C.M.; da Cunha, G.R.; Mansur, R.B.; Ota, V.K.; Belangero, S.I.; Cordeiro, Q.; Kapczinski, F; , et al. Ndel1 oligopeptidase activity as a potential biomarker of early stages of schizophrenia. Schizophr. Res. 2019, 208, 202-208. [CrossRef] [PubMed]

20. Sethi, S.; Hayashi, M.A.F.; Barbosa, B.S.; Pontes, J.G.M.; Tasic, L.; Brietzke, E. Lipidomics, Biomarkers, and Schizophrenia: A Current Perspective. In Metabolomics: From Fundamentals to Clinical Applications. Advances in Experimental Medicine and Biology; Sussulini, A., Ed.; Springer International Publishing: Cham, Switzerland, 2017; Volume 965, pp. 265-290.

21. Sethi, S.; Hayashi, M.A.F.; Sussulini, A.; Tasic, L.; Brietzke, E. Analytical approaches for lipidomics and its potential applications in neuropsychiatric disorders. World J. Biol. Psychiatry 2017, 18, 506-520. [CrossRef]

22. Sethi, S.; Pedrini, M.; Rizzo, L.B.; Zeni-Graiff, M.; Mas, C.D.; Cassinelli, A.C.; Noto, M.N.; Asevedo, E.; Cordeiro, Q.; Pontes, J.G.M.; et al. ${ }^{1} \mathrm{H}-\mathrm{NMR},{ }^{1} \mathrm{H}-\mathrm{NMR} \mathrm{T}_{2}$-edited, and 2D-NMR in bipolar disorder metabolic profiling. Int. J. Bipolar Disord. 2017, 5 , 1-9. [CrossRef]

23. Tasic, L.; Pontes, J.G.M.; Carvalho, M.S.; Cruz, G.; Dal Mas, C.; Sethi, S.; Pedrini, M.; Rizzo, L.B.; ZeniGraiff, M.; Asevedo, E.; et al. Metabolomics and lipidomics analyses by ${ }^{1} \mathrm{H}$ nuclear magnetic resonance of schizophrenia patient serum reveal potential peripheral biomarkers for diagnosis. Schizophr. Res. 2017, 185, 182-189. [CrossRef] [PubMed]

24. Tukiainen, T.; Tynkkynen, T.; Makinen, V.P.; Jylanki, P.; Kangas, A.; Hokkanen, J.; Vehtari, A.; Gröhn, O.; Hallikainen, M.; Soininen, H.; et al. A multi-metabolite analysis of serum by ${ }^{1} \mathrm{H}$ NMR spectroscopy: Early systemic signs of Alzheimer's disease. Biochem. Biophys. Res. Commun. 2008, 375, 356-361. [CrossRef]

25. Mor, N.C.; Correia, B.S.B.; Val, A.L.; Tasic, L. A protocol for fish lipid analysis using nuclear magnetic resonance spectroscopy. J. Braz. Chem. Soc. 2020, 31, 662-672. [CrossRef]

26. Li, J.; Vosegaard, T.; Guo, Z. Applications of nuclear magnetic resonance in lipid analyses: An emerging powerful tool for lipidomics studies. Prog. Lipid Res. 2017, 68, 37-56. [CrossRef] [PubMed]

27. Vidal, N.P.; Manzanos, M.J.; Goicoechea, E.; Guillén, M.D. Quality of farmed and wild sea bass lipids studied by ${ }^{1} \mathrm{H}$ NMR: Usefulness of this technique for differentiation on a qualitative and a quantitative basis. Food Chem. 2012, 135, $1583-1591$. [CrossRef]

28. Kaddurah-Daouk, R.; McEvoy, J.; Baillie, R.A.; Lee, D.; Yao, J.K.; Doraiswamy, P.M.; Krishnan, K.R.R. Metabolomic mapping of atypical antipsychotic effects in schizophrenia. Mol. Psychiatry 2007, 12, 934-945. [CrossRef]

29. He, Y.; Yu, Z.; Xie, I.G.L.; Hartmann, A.M.; Prehn, C.; Adamski, J.; Kahn, R.; Li, Y.; Illig, T.; WangSattler, R.; et al. Schizophrenia shows a unique metabolomics signature in plasma. Transl. Psychiatry 2012, 2, e149. [CrossRef]

30. Orešič, M.; Tang, J.; Seppänen-Laakso, T.; Mattila, I.; Saarni, S.E.; Saarni, S.I.; Lönnqvist, J.; Sysi-Aho, M.; Hyötyläinen, T.; Perälä, J.; et al. Metabolome in schizophrenia and other psychotic disorders: A general population-based study. Genome Med. 2011, 3, 1-14. [CrossRef]

31. Orešič, M.; Seppänen-Laakso, T.; Sun, D.; Tang, J.; Therman, S.; Viehman, R.; Mustonen, U.; van Erp, T.G.; Hyötyläinen, T.; Thompson, P.; et al. Phospholipids and insulin resistance in psychosis: A lipidomics study of twin pairs discordant for schizophrenia. Genome Med. 2012, 4, 1-10. [CrossRef]

32. McEvoy, J.; Baillie, R.A.; Zhu, H.; Buckley, P.; Keshavan, M.S.; Nasrallah, H.A.; Dougherty, G.G.; Yao, J.K.; Kaddurah-Daouk, R. Lipidomics reveals early metabolic changes in subjects with schizophrenia: Effects of atypical antipsychotics. PLoS ONE 2013, 8, e68717. [CrossRef]

33. Yao, J.K.; Stanley, J.A.; Reddy, R.D.; Keshavan, M.S.; Pettegrew, J.W. Correlations between peripheral polyunsaturated fatty acid content and in vivo membrane phospholipid metabolites. Biol. Psychiatry 2002, 52, 823-830. [CrossRef]

34. Simopoulos, A. The importance of the ratio of omega-6/omega-3 essential fatty acids. Biomed. Pharmacother 2002, 56, 365-379. [CrossRef]

35. Paul, R.; Choudhury, A.; Kumar, S.; Giri, A.; Sandhir, R.; Borah, A. Cholesterol contributes to dopamine-neuronal loss in MPTP mouse model of Parkinson's disease: Involvement of mitochondrial dysfunctions and oxidative stress. PLoS ONE 2017, 12, e0171285. [CrossRef]

36. Ward, K.M.; Yeoman, L.; McHugh, C.; Kraal, A.Z.; Flowers, S.A.; Rothberg, A.E.; Karnovsky, A.; Das, A.K.; Ellingrod, V.L.; Stringer, K.A. Atypical antipsychotic exposure may not differentiate metabolic phenotypes of patients with schizophrenia. Pharmacother. J. Hum. Pharmacol. Drug Ther. 2018, 38, 638-650. [CrossRef] 
37. Nandra, K.S.; Agius, M. The differences between typical and atypical antipsychotics: The effects on neurogenesis. Psychiatr. Danub. 2012, 24, S95-S99. [PubMed]

38. Nasrallah, H.; Chen, A. Multiple neurotoxic effects of haloperidol resulting in neuronal death. Ann. Clin. Psychiatry 2017, 29, 195-202. [PubMed]

39. Paul, R.; Dutta, A.; Phukan, B.C.; Mazumder, M.K.; Justin-Thenmozhi, A.; Manivasagam, T.; Bhattacharya, P.; Borah, A. Accumulation of cholesterol and homocysteine in the nigrostriatal pathway of brain contributes to the dopaminergic neurodegeneration in mice. Neuroscience 2018, 388, 347-356. [CrossRef]

40. Zhao, S.; Liao, W.; Xu, N.; Xu, H.; Yu, C.; Liu, X.; Li, C. Polar metabolite of cholesterol induces rat cognitive dysfunctions. Neuroscience 2009, 164, 398-403. [CrossRef]

41. Leoni, V.; Caccia, C. Study of cholesterol metabolism in Huntington's disease. Biochem. Biophys. Res. Commun. 2014, 446, 697-701. [CrossRef] [PubMed]

42. Moutinho, M.; Nunes, M.J.; Rodrigues, E. Cholesterol 24-hydroxylase: Brain cholesterol metabolism and beyond. Biochim. Biophys. Acta Mol. Cell Biol. Lipids 2016, 1861, 1911-1920. [CrossRef] [PubMed]

43. Petrov, A.M.; Kasimov, M.R.; Zefirov, A.L. Cholesterol in the pathogenesis of Alzheimer's, Parkinson's diseases and Autism: Link to synaptic dysfunction. Acta Nat. 2017, 9, 26-37. [CrossRef]

44. Solberg, D.K.; Bentsen, H.; Refsum, H.; Andreassen, O.A. Lipid profiles in schizophrenia associated with clinical traits: A five year follow-up study. BMC Psychiatry 2016, 16, 299. [CrossRef]

45. Shaikh, S.R.; Kinnun, J.J.; Leng, X.; Williams, J.A.; Wassall, S.R. How polyunsaturated fatty acids modify molecular organization in membranes: Insight from NMR studies of model systems. Biochim. Biophys. Acta Biomembr. 2015, 1848, 211-219. [CrossRef]

46. Horrobin, D.F. The membrane phospholipid hypothesis as a biochemical basis for the neurodevelopmental concept of schizophrenia. Schizophr. Res. 1998, 30, 193-208. [CrossRef]

47. Keshavan, M.S.; Mallinger, A.G.; Pettegrew, J.W.; Dippold, C. Erythrocyte membrane phospholipids in psychotic patients. Psychiatry Res. 1993, 49, 89-95. [CrossRef]

48. Mahadik, S.P.; Mukherjee, S.; Correnti, E.E.; Kelkar, H.S.; Wakade, C.G.; Costa, R.M.; Scheffer, R. Plasma membrane phospholipid and cholesterol distribution of skin fibroblasts from drug-naive patients at the onset of psychosis. Schizophr. Res. 1994, 13, $239-247$. [CrossRef]

49. Yang, J.; Chen, T.; Sun, L.; Zhao, Z.; Qi, X.; Zhou, K.; Cao, Y.; Wang, X.; Qiu, Y.; Su, M.; et al. Potential metabolite markers of schizophrenia. Mol. Psychiatry 2013, 18, 67-78. [CrossRef]

50. Schneider, M.; Levant, B.; Reichel, M.; Gulbins, E.; Kornhuber, J.; Müller, C.P. Lipids in psychiatric disorders and preventive medicine. Neurosci. Biobehav. Rev. 2017, 76, 336-362. [CrossRef]

51. Satogami, K.; Takahashi, S.; Yamada, S.; Ukai, S.; Shinosaki, K. Omega-3 fatty acids related to cognitive impairment in patients with schizophrenia. Schizophr. Res. Cogn. 2017, 9, 8-12. [CrossRef]

52. Rog, J.; Blazewicz, A.; Juchnowicz, D.; Ludwiczuk, A.; Stelmach, E.; Kozioł, M.; Karakula, M.; Nizinski, P.; Karakula-Juchnowicz, H. The role of GPR120 receptor in essential fatty acids metabolism in schizophrenia. Biomedicines 2020, 8, 243. [CrossRef] [PubMed]

53. Ward, K.; Citrome, L. Lisdexamfetamine: Chemistry, pharmacodynamics, pharmacokinetics, and clinical efficacy, safety, and tolerability in the treatment of binge eating disorder. Expert Opin. Drug Metab. Toxicol. 2018, 14, 229-238. [CrossRef] [PubMed]

54. Nani, J.V.; Lee, R.S.; Yonamine, C.; Dal Mas, C.; Sant'Anna, O.; Juliano, M.A.; Gadelha, A.; Mari, J.J.; Hayashi, M.A.F. Evaluation of NDEL1 oligopeptidase activity in blood and brain in an animal model of schizophrenia: Effects of psychostimulants and antipsychotics. Sci. Rep. 2020, 10, 18513. [CrossRef] [PubMed]

55. Hejr, H.; Ghareghani, M.; Zibara, K.; Ghafari, M.; Sadri, F.; Salehpour, Z.; Hamedi, A.; Negintaji, K.; Azari, H.; Ghanbari, A. The ratio of $1 / 3$ linoleic acid to alpha linolenic acid is optimal for oligodendrogenesis of embryonic neural stem cells. Neurosci. Lett. 2017, 651, 216-225. [CrossRef]

56. Bourre, J.M.; Dumont, O. Dietary oleic acid not used during brain development and in adult in rat, in contrast with sciatic nerve. Neurosci. Lett. 2003, 336, 180-184. [CrossRef]

57. Bourre, J.M. Roles of unsaturated fatty acids (especially omega-3 fatty acids) in the brain at various ages and during ageing. $J$. Nutr. Health Aging 2004, 8, 163-174. [PubMed]

58. Berman, S.M.; Kuczenski, R.; McCracken, J.T.; London, E.D. Potential adverse effects of amphetamine treatment on brain and behavior: A review. Mol. Psychiatry 2009, 14, 123-142. [CrossRef]

59. Thomas, D.M.; Francescutti-Verbeem, D.M.; Kuhn, D.M. The newly synthesized pool of dopamine determines the severity of methamphetamine-induced neurotoxicity. J. Neurochem. 2008, 105, 605-616. [CrossRef] [PubMed]

60. Park, S.W.; Seo, M.K.; McIntyre, R.S.; Mansur, R.B.; Lee, Y.; Lee, J.-H.; Park, S.-C.; Huh, L.; Lee, J.G. Effects of olanzapine and haloperidol on mTORC1 signaling dendritic outgrowth, and synaptic proteins in rat primary hippocampal neurons under toxic conditions. Neurosci. Lett. 2018, 686, 59-66. [CrossRef]

61. Tessier, C.; Nuss, P.; Staneva, G.; Wolf, C. Modification of membrane heterogeneity by antipsychotic drugs: An X-ray diffraction comparative study. J. Colloid Interface Sci. 2008, 320, 469-479. [CrossRef] 